\title{
Playing the policy game: a review of the barriers to and enablers of nutrition policy change
}

\author{
Katherine Cullerton ${ }^{1, *}$, Timothy Donnet ${ }^{2},{\text { Amanda } \text { Lee }^{3} \text { and Danielle Gallegos }}^{1}$ \\ ${ }^{1}$ School of Exercise and Nutrition Sciences, Queensland University of Technology, Victoria Park Road, Kelvin Grove, \\ QLD 4059, Australia: ${ }^{2}$ School of Management, Queensland University of Technology, Brisbane, Queensland, \\ Australia: ${ }^{3}$ School of Public Health and Social Work, Queensland University of Technology, Kelvin Grove, \\ Queensland, Australia
}

Submitted 24 November 2015: Final revision received 10 February 2016: Accepted 1 March 2016: First published online 1 April 2016

\begin{abstract}
Objective: To progress nutrition policy change and develop more effective advocates, it is useful to consider real-world factors and practical experiences of past advocacy efforts to determine the key barriers to and enablers of nutrition policy change. The present review aimed to identify and synthesize the enablers of and barriers to public policy change within the field of nutrition.

Design: Electronic databases were searched systematically for studies examining policy making in public health nutrition. An interpretive synthesis was undertaken. Setting: International, national, state and local government jurisdictions within high-income, democratic countries.

Results: Sixty-three studies were selected for inclusion. Numerous themes were identified explaining the barriers to and enablers of policy change, all of which fell under the overarching category of 'political will', underpinned by a second major category, 'public will'. Sub-themes, including pressure from industry, neoliberal ideology, use of emotions and values, and being visible, were prevalent in describing links between public will, political will and policy change.

Conclusions: The frustration around lack of public policy change in nutrition frequently stems from a belief that policy making is a rational process in which evidence is used to assess the relative costs and benefits of options. The findings from the present review confirm that evidence is only one component of influencing policy change. For policy change to occur there needs to be the political will, and often the public will, for the proposed policy problem and solution. The review presents a suite of enablers which can assist health professionals to influence political and public will in future advocacy efforts.
\end{abstract}

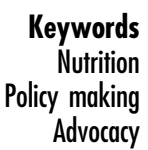

Improving the nutritional status of populations remains an urgent priority for addressing the growing burden of obesity and chronic disease worldwide ${ }^{(1)}$. Recent papers advocate that the most effective way of achieving this involves the promotion and implementation of public policy change, focusing on regulation, legislation and public awareness campaigns designed to make healthy food choices the preferred choice ${ }^{(1,2)}$. However, relevant political science theory highlights that changing policy at a national, state or local level of government is a slow and often challenging process due to the complexity of the policy change process and the conservative nature of political systems, which favour the status quo ${ }^{(3)}$. Research from policy process scholars suggests this preference towards the status quo is due to: institutions' resistance to change; constraints on the rationality of decision makers due to limited time and the cognitive overload they face; and the power of vested interests in maintaining their privileged position ${ }^{(3,4)}$. For change to occur, therefore, the power of vested interests needs to be challenged and the policy problem, the policy solution and the political climate all need to $\operatorname{align}^{(3,4)}$.

Nutrition advocates from non-government organisations, academia and government bodies have taken up the challenge by attempting to influence policy positively through a range of advocacy strategies, with varied success $^{(5)}$. Advocacy is defined as 'active interventions by organisations on behalf of the collective interests they represent, that has the explicit goal of influencing public policy or the decisions of any institutional elite' (p. 643) ${ }^{(6)}$. Some interest groups have greater power to influence public policy and decision making than others due to their organisational or personal resources, including knowledge of effective advocacy strategies and how to apply them. For groups in positions of low power and influence, 
Table 1 Summary of influential theories of the policy process ${ }^{(10)}$

\begin{tabular}{|c|c|c|c|}
\hline & Advocacy Coalition Framework & Multiple Streams Theory & Punctuated-Equilibrium Theory \\
\hline Summary & $\begin{array}{l}\text { Policy making is characterised } \\
\text { by the interaction of } \\
\text { advocacy coalitions within a } \\
\text { policy subsystem }\end{array}$ & $\begin{array}{l}\text { Policy making is composed of three } \\
\text { streams: problem; policy; politics. } \\
\text { These streams come together during } \\
\text { windows of opportunity to cause policy } \\
\text { change }\end{array}$ & $\begin{array}{l}\text { Policy making is characterised by } \\
\text { long periods of incremental change } \\
\text { punctuated by brief periods of major } \\
\text { policy change }\end{array}$ \\
\hline $\begin{array}{l}\text { Individual } \\
\text { motivation }\end{array}$ & $\begin{array}{l}\text { Belief system guides choices } \\
\text { and actions }\end{array}$ & $\begin{array}{l}\text { Assesses options until an acceptable } \\
\text { solution is found }\end{array}$ & $\begin{array}{l}\text { Salience of an issue depends } \\
\text { on context }\end{array}$ \\
\hline $\begin{array}{l}\text { Drivers of policy } \\
\text { change }\end{array}$ & $\begin{array}{l}\text { Alignment and activity of } \\
\text { coalitions. Outside factors } \\
\text { can realign beliefs and } \\
\text { generate change }\end{array}$ & $\begin{array}{l}\text { Opening of policy windows capitalised } \\
\text { on by policy entrepreneurs }\end{array}$ & $\begin{array}{l}\text { Policy image and public mobilisation can } \\
\text { establish a new policy monopoly. } \\
\text { Entrepreneurs and interests groups } \\
\text { play a role }\end{array}$ \\
\hline
\end{tabular}

improving knowledge of effective advocacy strategies and how to apply them, particularly under resource-constrained conditions, could change the power dynamic between policy makers and the people affected by their decisions ${ }^{(7)}$.

Internationally, a limited range of peer-reviewed literature documents effective advocacy strategies for influencing public health policy in general, with even less literature on influencing public health nutrition policy ${ }^{(8)}$. Political science is one field where a large volume of research has occurred in the study of the policy process and influencing policy change ${ }^{(3,4,9)}$; see Table 1 for a summary of influential policy process theories. While theoretical models and frameworks from political science can guide practitioners in influencing the policy-making process, only limited numbers of nutrition policy advocates utilise these theories when championing policy change ${ }^{(10)}$. One criticism of these theories, which may explain their limited use, is that they have been designed for an academic audience, rather than a practitioner audience, with concepts that are often difficult to understand and translate to the real world ${ }^{(11)}$.

To progress nutrition policy change and develop more effective advocates, it is useful to consider the real-world factors and practical experiences of past advocacy efforts to determine the barriers to and enablers of nutrition policy change. Understanding these barriers and enablers may ensure future advocacy efforts of health professionals are more targeted with interventions tailored to address specific barriers and to make use of specific enablers. To date, there has been only one review examining advocacy in nutrition policy undertaken and it focused specifically on obesity prevention ${ }^{(12)}$. No systematic review has been conducted of the barriers to and enablers of nutrition policy change. To address this gap in knowledge, the current paper presents a systematic review of the barriers to and enablers of nutrition policy change, with a specific focus on high-income, democratic countries.

\section{Methodology}

The current review reanalyses the results of a previous systematic literature review ${ }^{(10)}$ to answer a new question.
These data were first used to determine whether policy process theory had been used in nutrition policy papers. As the majority did not use policy process theory, the data were reassessed via interpretive synthesis ${ }^{(13)}$ to determine the enablers of and barriers to public health nutrition policy change. The search strategy has been reported elsewhere $^{(10)}$ and is summarised below.

The systematic review was conducted based on the PRISMA (Preferred Reporting Items for Systematic Reviews and Meta-Analyses) statement (Fig. 1) and a review protocol developed by Breton and De Leeuw ${ }^{(14)}$. Five electronic databases (PubMed, Informit, CINAHL, PsycINFO and Scopus) were searched using the inclusion and exclusion criteria specified in Table 2. The application of the criteria resulted in 147 eligible papers progressing to the next stage in the screening process.

These papers were read fully by the first author (K.C.) and assessed as to whether barriers to and enablers of influencing public health nutrition policy were identified. When there was uncertainty as to whether a paper fit the inclusion criteria, it was reviewed by a second author (D.G.). Disagreements were resolved by discussion until consensus was reached. As a means of controlling for comparable systems of policy making, a second screening excluded all papers focused on low-income and/or partial or non-democratic countries as defined by the Democracy Index $2014\left(n\right.$ 19) ${ }^{(15)}$.

\section{Analysis}

The Framework Method ${ }^{(16)}$ was adapted to guide the analysis of the data. This is a systematic thematic analysis process which identifies commonalities and differences in qualitative data before focusing on relationships between different parts of the data ${ }^{(17)}$. Papers were coded line by line by one investigator (K.C.). Initial codes were a mix of open and predefined codes informed by the following political science policy process theories: the Advocacy Coalition Framework; the Punctuated-Equilibrium Theory; and Multiple Streams Theory ${ }^{(3,4,9)}$. The predefined codes from the literature included: policy entrepreneur; policy window; and coalition. The remaining codes were deduced from the data. After coding six papers a working 


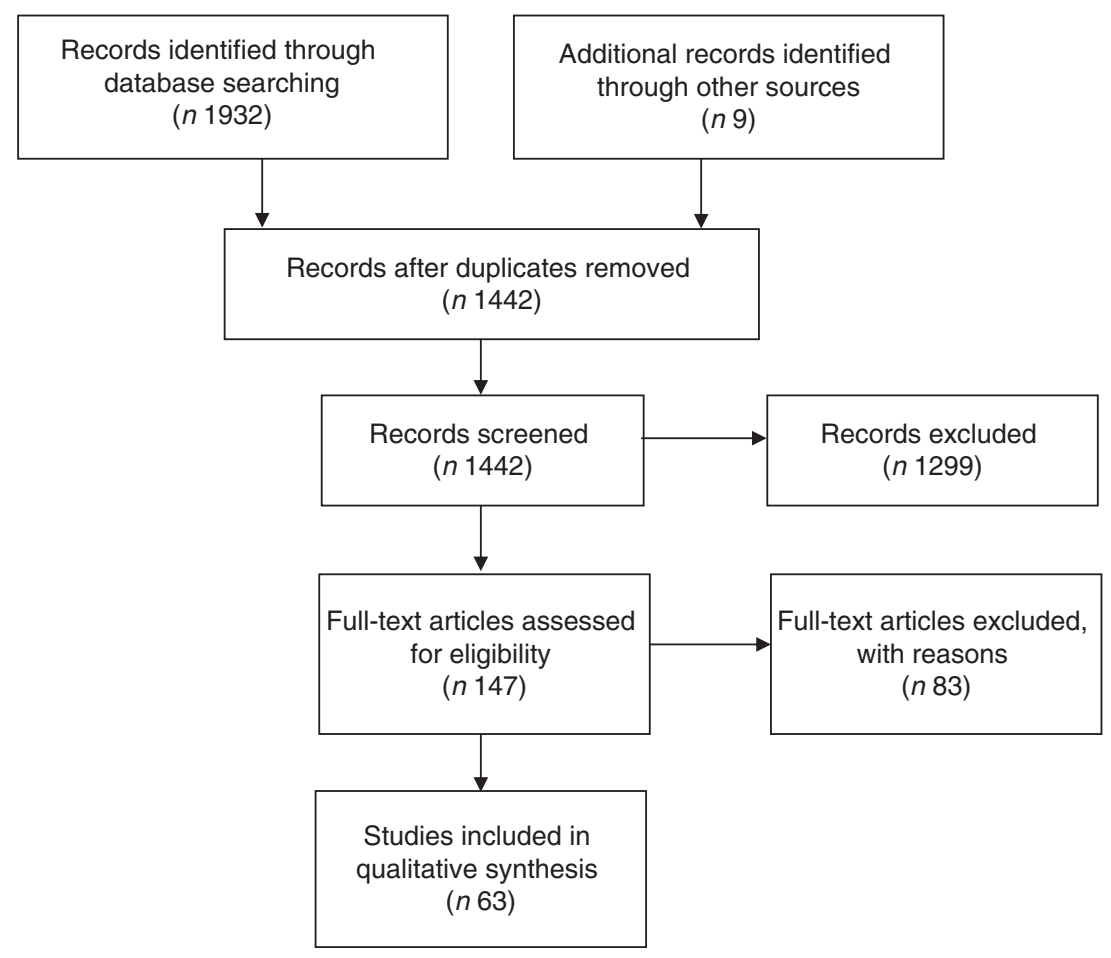

Fig. 1 PRISMA 2009 flow diagram

Table 2 Inclusion and exclusion criteria for the identification of journal articles reporting on policy research

\section{Inclusion criteria}

The article:

- Is in a peer-reviewed journal indexed in PubMed, Scopus, Informit, CINAHL or PsycINFO.

- Is in English.

- Was published between January 1986 and December 2014.

- Features in its abstract, title or subject headings the search terms: '(politic* OR advoc* OR coalition OR influenc*) AND (nutri ${ }^{\star}$ OR food OR obesity) AND (polic*) AND (government)'. When more than 500 papers were retrieved from a search, the terms AND NOT (school* OR agriculture*) were included.

- Reports on issues at the supra-national, national, state or local government level related to:

- The content or nature of a policy, i.e. (foreseen) components, effectiveness, impact, evolution.

- The policy change process, i.e. advocacy intervention or strategy, capacity building for advocacy, evidence and knowledge shaping in policy making, theoretical and methodological issues in policy analysis. Addresses a policy or policy process that goes beyond the walls of a specific workplace, school or other organisational setting.

Exclusion criteria

The article refers to:

- Policies related to a specific setting, e.g. workplace, school or other organisational setting.

- Policies related to clinical nutrition issues, e.g. hospital-based or one-to-one dietetic services.

- Policies related to general well-being, physical activity, tobacco or agriculture.

- An opinion piece, commentary, letter or book review.

analytical framework, which incorporated the codes, was applied to each paper. However, there was flexibility to add new codes if needed. The qualitative data analysis software NVivo 10 (QSR International; 2012) was used to manage the data and to generate the analytical framework.

Once the analytical framework had been applied, the characteristics of and differences between the data were identified. This was followed by mapping the connections between these categories and identifying the central themes that emerged which characterised and represented the key enablers and barriers. Throughout this process, the range of attitudes and experiences, including deviant cases for each theme, was considered. As this was an interpretive review $^{(13)}$, no attempt was made to undertake a content analysis in order to differentiate the themes in terms of dialogue frequency and/or importance.

\section{Results and discussion}

Screening resulted in sixty-three studies included for analysis. The characteristics of these studies can be found in a previous paper ${ }^{(10)}$. Numerous themes were identified explaining the barriers to and enablers of policy change, all of which fell under the overarching category of 'political will'. Political will reflects whether or not decision makers (politicians or senior bureaucrats) were supportive of policy change. This was underpinned by a second major category, 'public will', which reflects the mood and policy preferences of voters. Public will was a major component of political will, as politicians were often not motivated to act on an issue that had little public interest or could cause a backlash from wider society ${ }^{(18)}$. 


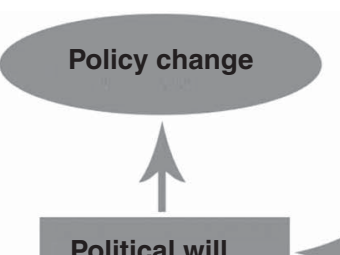

Political will

Public will

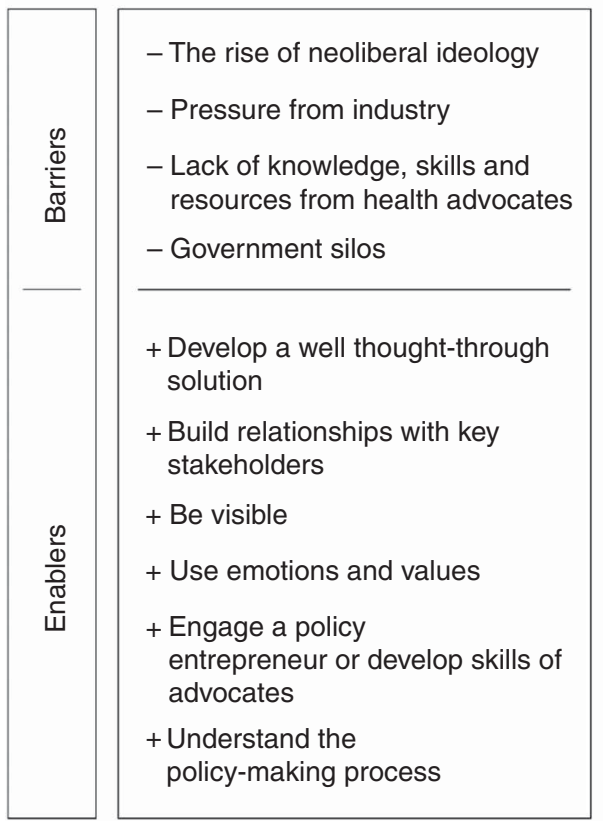

$$
\begin{aligned}
& \text { - The rise of neoliberal ideology } \\
& \text { - Pressure from industry } \\
& \text { - Lack of knowledge, skills and } \\
& \text { resources from health advocates } \\
& \hline \text { + Develop a well thought-through } \\
& \text { solution } \\
& + \text { Build relationships with key } \\
& \text { stakeholders } \\
& + \text { Be visible } \\
& + \text { Use emotions and values }
\end{aligned}
$$

Fig. 2 The barriers to and enablers of political and public will

Four themes emerged as barriers and six as enablers for political will, while three themes emerged as barriers and four as enablers for public will. There was high concordance between the themes connected to influencing public and political will (see Fig. 2).

\section{Barriers to change in policy making}

The barriers to policy change included: the rise of neoliberal ideology; pressure from industry; lack of knowledge, skills and resources from health advocates; and government silos. These themes all fell under the overarching theme of political will and all, except government silos, were also applicable to the second overarching theme of public will.

\section{The rise of neoliberal ideology}

The influence of neoliberal ideology in policy decisions was evident throughout the literature. Several papers referred to the prioritising of economic prosperity as the main barrier to policy change ${ }^{(18-23)}$. This was demonstrated by a lack of support for regulatory intervention, with the justification that it could interfere with market-driven economies ${ }^{(24)}$. Furthermore, the cost of implementing proposed solutions and monitoring compliance was also cited as a concern to governments ${ }^{(20,24,25)}$. Specifically, many countries now require government departments proposing regulation to demonstrate that they are cost-saving; that is, the health benefits directly attributed to the regulation will exceed the direct or indirect costs to business ${ }^{(24,25)}$. This was problematic for many public health nutrition initiatives as evidence around cost-effectiveness did not exist or was difficult to determine due to the complexity and multifactorial nature of nutrition problems ${ }^{(25-27)}$.

Prioritisation of government policies that resulted in shortterm economic benefit, over policies related to longer-term health outcomes, was also evident in the literature. This prioritisation was apparent when agricultural policies based on subsidies raised the relative price of healthy foods and lowered the price of unhealthy foods ${ }^{(18,23,24,28,29)}$. In addition, conflicted decision making was seen when the government department responsible for protecting agricultural producers was the same department advising the public about dietary intake ${ }^{(28)}$. This conflict was evident when the US Department of Agriculture, which had a dual mandate for health and agriculture, under pressure from meat producers, changed federal dietary advice from 'decrease consumption of meat' to 'have two or three (daily) servings ${ }^{(28)}$. Even within health departments, there were competing agendas which prioritised certain nutrition issues over others, for example food safety over food security ${ }^{(30)}$. 
Some authors identified the overriding desire by governments to ensure personal freedoms was a driver in eschewing regulation or 'nanny state' options. As Campbell $^{(31)}$ pointed out, proposing legislation as a solution creates tension within nations with a liberal tradition of personal responsibility, individual choice and free markets. This ideological conflict was identified by several authors who documented a change in government resulting in food and nutrition policies being watered down or rescinded on the basis of the revised policy being more industry friendly, or because of personal responsibility arguments ${ }^{(5,22,26)}$. It should be noted that the ideology of personal responsibility is an entity in its own right albeit strongly influenced by industry as a strategy to increase consumption ${ }^{(32)}$.

\section{Pressure from industry}

Pressure from industry was one of the main barriers cited for policy change not occurring. This came in a number of forms, including intense lobbying; creation of scientific uncertainty; industry-government or professional body partnerships; and influencing cultural norms.

Intense lobbying. The most noticeable form of pressure from industry was intense lobbying ${ }^{, 5,22,23,26,28,31,33)}$. Although it should be noted that several authors referred to industry 'using their influence', there was no elaboration on what this involved ${ }^{(22,23)}$. Dodson et al. ${ }^{(34)}$ elaborated by stating that lobbyists were ever present and that they 'watch for issues a lot more carefully than public interest groups'. Gilson Sistrom ${ }^{(33)}$ concurred with this and stated that through their higher capacity and resources, industry lobbyists were able to 'dog' legislators every day. In addition, it was noted that industry had a lot more points of interaction with government than health organisations as providers of tax revenue, major employers, through international linkages, and as holders of specialised knowledge ${ }^{(35)}$. Other food industry strategies mentioned included contributing directly to political parties or individual politicians ${ }^{(28,36,37)}$ and utilising high-level contacts $^{(24,32)}$.

Creation of scientific uncertainty. Another form of pressure evident in the literature was industry claiming there was insufficient evidence on effective interventions and that more evidence was needed before further action occurred $^{(27,32,35,38)}$. This strategy generated a level of uncertainty regarding evidence and tended to reduce the authority of health professionals advocating for action $^{(27,32,35)}$. Another strategy was for industry to fund scientific research to support its viewpoint or to spread unsubstantiated misinformation ${ }^{(32,38,39)}$. Consequently, this allowed industry to control how the issue was portrayed to policy makers and the general public.

Industry-government or professional body partnerships. Forming associations with professional bodies and government agencies allowed industry to build citizens' trust in systems they perceived to be ethically flawed or puzzling ${ }^{(40)}$. Badging or developing a formal relationship with a nutrition organisation was seen as a third-party endorsement for a company and gave it legitimacy to intervene in the regulatory environment ${ }^{(32,40)}$. Industrygovernment partnerships allowed industry to shape a supportive regulatory environment that did not impact on corporate profits ${ }^{(32,35,38,40,41)}$. A more concerning aspect of this was where public policy was not simply influenced but actually co-created and delivered by the private sector, for example the 'Change4Life' campaign in the $\mathrm{UK}^{(41-43)}$.

Influencing cultural norms. Industry's pursuit of competitive advantage requires the active shaping of the cultural environment in which food choices are made $^{(40,42)}$. Consequently, industry invested considerable resources to control the frame around nutrition problems and solutions. Framing is how an issue is portrayed, often using media to influence popular and elite opinion ${ }^{(39)}$. One effective way issues were framed and reported in the media was that regulation violates freedom of expression and limits personal responsibility ${ }^{(32,35)}$. This effectively links in with the pursuit of the neoliberal agenda and increases the value of industry as a government ally. A further strategy to influence cultural norms was manufacturing public sentiment through the use of 'fake' citizen groups funded by the food industry, for example 'The Obesity Awareness and Solutions Trust' ${ }^{\text {(42) }}$. Miller and Harkins ${ }^{(42)}$ concluded that this strategy was effective because it plays on the fears of politicians of a backlash from wider society.

Lack of resources, skills and knowledge from health advocates

The limited resources, money and time of health advocates were cited as significant barriers to policy change ${ }^{(20,34,37)}$. The volunteer advocates in the Oregon Healthy Foods Schools Bill felt themselves to be at a distinct disadvantage against paid, full-time lobbyists. They did not have the time or money to directly lobby decision makers and adding to this disadvantage was that they did not understand the policy and political processes ${ }^{(33)}$.

Confusion over the policy-making process was a key barrier for health advocates and components of this included: not knowing the entry point or responsibility of government departments for certain nutrition issues ${ }^{(21)}$; not understanding that politicians usually decide on whether policy goes ahead, not the bureaucrats ${ }^{(25)}$; the importance of a uniform voice ${ }^{(33)}$; the dogged persistence that is required ${ }^{(33)}$; and the hierarchy of power within government departments ${ }^{(24)}$. Also, some advocates' inability to compromise meant that they missed out on opportunities for policy progression ${ }^{(33,37)}$.

Poor communication of the solution. The most commonly identified communication issue in the literature was advocates not comprehending how little time policy makers have to understand an issue ${ }^{(20,21,44,45)}$. Food and 
nutrition policy is complex and multifactorial; however, policy makers are often required to make decisions with limited time. Providing reams of evidence or using complex language was not helpful for policy makers, as most do not have the time required to summarise and understand best practice solutions ${ }^{(20,21,45,46)}$. Furthermore, ineffective framing of the issue weakened arguments and shifted the focus away from interventions or policies of worth ${ }^{(39)}$.

\section{Government silos}

Dietary intake is influenced by a complex set of factors and as a result the responsibility is spread across different government departments and different levels of government ${ }^{(23,25)}$. Coordinating various departments to work together can be challenging as they tend to work in 'silos' and prioritise their own objectives ${ }^{(20,24)}$. Furthermore, some government departments can take a narrow perspective of their responsibilities, for example: local government identifying its sole role in food policy as the regulation of food hygiene and safety ${ }^{(21)}$; and Departments of Agriculture seeing food only as a product to grow, sell and export ${ }^{(22,29,47)}$. These narrow perspectives were also reinforced by a broader societal mindset around a biomedical approach to health; that is, that treatment and management take priority over prevention $^{(21)}$.

\section{Enablers of policy change}

As highlighted in Fig. 2, the literature pointed to a wide array of enablers that can be harnessed to improve the likelihood of positive policy change. All were focused on building political and/or public will, as detailed below.

\section{Develop a well thought-through solution}

A key enabler of policy change that emerged from the literature was providing policy makers, and often the general public, with a well thought-through solution $^{(12,25,48,49)}$. The most successful solutions had several components: clear, costed strategies on how to solve the problem; single or incremental strategies; and a local focus.

Clear, costed strategies on bow to solve the problem (technical feasibility). Many of the included studies described the importance of evidence in the policymaking process. However, several caveats were provided regarding the need to ensure evidence is useful for policy makers (see Table 3).

Offer single or incremental solutions. A potential source of confusion for advocates in the complex field of public health nutrition is whether to put forward a package of interventions which will have a far greater impact on health status, or put forward one, manageable intervention which would have a more limited impact ${ }^{(25)}$. All but one of the studies that examined this issue suggested one single intervention or incrementalism had a far greater chance of
Table 3 Making evidence useful for policy makers

- Present practical and suitable solutions not just problems $^{(12,48,51,62)}$.

- Highlight successful international implementation of the proposed solution $^{(12,47,49)}$.

- Explicitly describe the way an idea would be brought into practical use, including all implementation issues and the potential impact of the policy (including cost to business) ${ }^{(12,25,48)}$.

- Keep documents brief, two pages or less ${ }^{(46)}$.

- Include information on efficiency and whether benefits could be achieved through less costly policy options to help combat the views of competitors ${ }^{(12,25)}$.

- Ensure solutions are aimed at a wide audience; and provide information on the number, proportion and representativeness of individuals likely to be affected by the proposed solution ${ }^{(12)}$.

- While it is important to seek out the best available evidence, it may be necessary to include untested yet promising strategies $^{(12)}$.

enactment $^{(34,50-52)}$. Opposing this view was one study that suggested providing a package of interventions was more effective, as the government requirements of costeffectiveness could not be demonstrated with just one intervention $^{(25)}$. It was also suggested that advocates should always have a list of backup ideas to allow flexibility during negotiations or when a different window of opportunity opens ${ }^{(12)}$.

Start locally. Starting locally was found to be another way to present a more manageable proposal to policy makers. Local advocacy initiatives were more effective in achieving their objectives than national ones ${ }^{(51,53)}$. This success may be because they set more modest goals, defined a more manageable scope of activities, or the institutional structures of local government are not as complex with fewer vested interests than at the state or national level. Compared with state- and nationally focused initiatives, local initiatives were able to leverage funding and support through different, often less competitive routes $^{(54)}$. However, while this strategy can be successful at a local level, there was limited evidence of success at 'scaling up' to the national policy level ${ }^{(55)}$.

\section{Build relationships with key stakeholders}

Gaining support from a wide range of policy makers and key stakeholders increased the chance of legislation passing or a policy solution being supported ${ }^{(12,34,50,54,54)}$. Stakeholder support to which decision makers responded positively included their constituencies and colleagues, including public officials, community leaders and interest groups $^{(12,50,54,56)}$. Consequently, those advocates who did not engage with key stakeholders found their position was weakened ${ }^{(35)}$. By building relationships with key stakeholders, advocates developed a greater understanding of the wider environment and were able to identify policy opportunities, tailor policy options to the existing political environment, and gauge the likelihood of success ${ }^{(12,57)}$. 
Form diverse and well-connected coalitions. Forming coalitions encompasses formally bringing together interest groups and organisations, and sometimes politicians, to strengthen the voice on an issue and influence policy change. Establishing broad engagement and commitment across a mix of stakeholders, particularly non-traditional alliances, for example agricultural and producer interests, contributed to the building of a strong coalition which was able to exert prevailing influence on policy decisions $^{(12,30,34,47,50,51,53,56,58)}$. One example of this was the Washington Nutrition Obesity Policy Research and Evaluation Network which included researchers, public health practitioners, and advocates from nutrition, agriculture, law, economics, public policy, epidemiology and urban design ${ }^{(58)}$. Another advantage of fostering diversity was that all parties can provide complementary skills, resources, and new strategies and contacts to move towards the common policy goal ${ }^{(12,20,51,53,58,59)}$. Furthermore, coalitions that included groups with access to key points of government and decision making were more likely to have their issue placed on an agenda ${ }^{(12)}$. Others highlighted the advantages of the often contentious strategy of forming a coalition with industry to reach mutually agreeable solutions on nutrition issues ${ }^{(49,60)}$

Choose one common goal. When issues become linked based on a common goal, this creates synergy rather than competition and increases the likelihood of policy change $^{(59)}$. Conversely, disunity among interest groups creates confusion and weakens each interest group's position. Such disunity, and the ensuing lack of change, was evident in two papers: the debate on a proposed tax on sugar-sweetened beverages, where hunger activists said the tax unfairly hurt the poor ${ }^{(59)}$; and legislation to improve school meals in Oregon, which was met with opposition from parents, teachers and food-service professionals as they wanted to protect profits and keep local control $^{(33,34)}$. Disunity through a lack of coordination was identified as a barrier by Field and Gauld ${ }^{(35)}$ in a government inquiry into food marketing to children where multiple advocacy groups participated. However, there was little coordination in their advocacy efforts, which weakened their overall position, resulting in failure to influence the outcome of the inquiry.

\section{Use emotions and values}

While using evidence was cited as important, other factors, such as using stories and emotion to engage values, can be equally, if not more, compelling ${ }^{(12,39,46)}$. A popular technique for building support and political will among policy makers and the general community by way of emotions and values was framing. Small changes in how an issue is presented can significantly alter how an issue is understood, which can result in a change in public opinion as well as the policy-making environment ${ }^{(39,46,54,61)}$. The most effective frames relied on simple messages that were easy for the general public and politicians to $\operatorname{grasp}^{(43,45)}$. Frames that advocates successfully used to build policy support included: protecting the health of children; truth and honesty; fairness and social justice; and urgent crisis or a looming evil ${ }^{(18,53,62,63)}$. Safeguarding children seemed particularly effective with neoliberal governments where there was concern about excessive government control over individuals and food choices $^{(63)}$.

\section{Be visible}

To be effective, advocates must first have their issue acknowledged by policy makers as a problem worthy of attention. Being visible is one way to get your issue acknowledged. Visibility can come in a variety of forms but often requires high-level communication skills and creative solutions $^{(64)}$. The various techniques highlighted in the literature are presented below.

High-profile event or report. A large number of studies found that attendance by policy makers at a high-profile event or policy makers reading a prominent, salient report was the trigger point for initiating policy action on an issue $^{(20,26,28,45,47,51,62,63)}$. Creating documents or events that either raised awareness of an issue of which policy makers previously were unaware or/and clearly outlined steps to solve the problem were considered most effective. Effectively framing the problem and utilising international data or targets as a comparison also came up as important ways to attract attention and encourage action to be taken $^{(12,45,47,62,63)}$.

Media engagement or campaign. Advocacy coalitions that engaged with the media frequently were more likely to achieve policy change ${ }^{(12,34)}$. However, it was noted that engaging the media can be challenging for health advocates due to a lack of media skills and experience $^{(12)}$. Specific strategies that were successful included leveraging media coverage off national and international stories ${ }^{(54)}$ and using high-profile organisations or individuals to attract media attention ${ }^{(18,62)}$. Using high-profile organisations or individuals also provided credibility to issues with policy makers and the general public $^{(18,55,62)}$.

Public mobilisation. Mobilising wider society to demonstrate support for an issue led to increased public and political will. Historically, this has been a frequently used strategy of health advocates in the form of rallies, mass email communications and boycotts ${ }^{(36,53)}$. This is a very visible way of demonstrating public support to policy makers. Alternatively, public surveys and interviews with key opinion leaders can also demonstrate the support of the public ${ }^{(12)}$. Providing public education or community workshops about the topic at hand and policy solutions may be required before the public engages and becomes mobilised $^{(12,20,34,47,61)}$. Conversely, failing to mobilise community support was identified as a key reason for a policy issue not getting policy makers' support ${ }^{(33)}$. 
Engage a policy entrepreneur or develop skills of advocates The value of a 'policy entrepreneur', described as an 'advocate for proposals or for the prominence of an idea, in progressing policy change,(4), was highlighted in many studies. Often the policy entrepreneur was in a position of power, for example a local government chief executive officer or a politician ${ }^{(21,30,45,54,63,65)}$, but not always $^{(20,34,51,66)}$. Regardless of position, policy entrepreneurs were seen as effective conduits for disseminating evidence to legislators and for promoting recommended strategies $^{(20,47,50,51,62)}$. The skills of the policy entrepreneur were often extolled in the literature, these included: their analytical, strategic and political policy skills; high-level communication skills which enabled them to negotiate with, influence and encourage consensus among high-level stakeholders; and their general passion, enthusiasm and vision for the issue at stake $(20,47,51,62,65,67)$.

Other attributes of a successful policy entrepreneur were the need to be flexible, adaptive and persistent. Practically, this meant being able to refine policy solutions in line with the politics of the time ${ }^{(22,47)}$ and being open to compromise by offering alternative solutions that were mutually agreeable between interested parties ${ }^{(33,37)}$. Moreover, this required policy entrepreneurs to be nimble enough to take advantage of new political opportunities when they arose and to understand the strategies and end goal of their opposition ${ }^{(20,33,48)}$. Finally, policy making is a long process and so persistence was required $^{(47,67)}$.

\section{Understand the policy-making process}

Lack of understanding of the policy-making process emerged as a barrier to policy change in the literature; however, key strategies were identified to overcome this.

Ensure solutions are politically palatable. For a solution to be politically palatable it needed to align with at least one goal of the government as well as the prevailing political ideology ${ }^{(25,40,48)}$. If a policy does not align with the prevailing neoliberal view, it is unlikely to make it on the agenda despite the advocate's best efforts. Additionally, interventions that are 'announceable' - that is, they are not contentious and the government receives favourable press coverage - needed to be offered ${ }^{(27,54)}$. Clearly demonstrating community benefit increased the political palatability of a policy solution ${ }^{(21,27,54)}$. Finally, avoiding all conflict with, or criticism of, the policies of government ensured an advocate or organisation remained politically neutral $^{(54)}$. However, as pointed out by Bedore ${ }^{(54)}$ this strategy required advocates to relinquish the opportunity to be critical of the ethics of decision making and the existing power structures that impact on the food system, social welfare and health.

Responding to the desire to keep wider society 'on board', policy makers tended to choose interventions which were the least intrusive and thereby least likely to cause disquiet among target populations ${ }^{(21)}$. There was a
Table 4 Strategies to strategically target decision makers

- Develop knowledge of influential networks that elected and appointed officials are situated within, including key decision makers' colleagues, community and business affiliations, donors and political supporters ${ }^{(12)}$.

- In these networks, identify the least resistant part of the policy nexus and target evidence towards this entry point ${ }^{(21)}$.

- Encourage support from a wide range of politicians as policy is more likely to be enacted if there is bipartisan support ${ }^{(50)}$.

- Progressive parties are more likely to support public health nutrition initiatives; this may mean waiting for a change in government or targeting a different level of government which may have a more supportive political environment ${ }^{(68)}$.

- Target decision makers as senior as possible as the higher level of bureaucracy is where policy is being formed and they are more open to innovation ${ }^{(48)}$.

- Target bureaucrats and politicians with personal experience of the issue ${ }^{(45)}$.

preference for voluntary action solutions to avoid battles between stakeholders and long regulatory processes to enact such laws. In the studies reviewed, policy makers were more supportive of non-legislative solutions, despite the effectiveness of these being limited ${ }^{(23,24,27,35,45,52,67,68)}$. Particularly popular solutions were: health and nutrition education in schools ${ }^{(45,50,68)}$; developing and promoting nutrition guidelines ${ }^{(23)}$ or taskforces ${ }^{(5,27,45,50)}$; cooking classes and community vegetable gardens ${ }^{(67)}$; school canteen recommendations/toolkits ${ }^{(27,45)}$; voluntary salt reduction $^{(52)}$; and collaborations with industry ${ }^{(24,35,41)}$.

Strategically target decision makers. Advocates who did not understand the policy-making process often did not know who to target. Several strategies were identified to overcome this (see Table 4).

Be nimble (ready for the policy window). Successful policy change often hinges on understanding how and when the processes of problem recognition, policy development and political decision making converge. The coupling of these domains is commonly referred to as the opening of a policy window, representing an advantageous time for policy change ${ }^{(12)}$. A theme throughout the papers was that advocates need to be nimble and ready for the policy window ${ }^{(18,22,39,33,53)}$. Identifying and being prepared to take advantage of new political opportunities when they arise is crucial as missing that window will mean the policy solution will fall on deaf ears ${ }^{(18,22,34)}$. Alternatively, it was important to be realistic when the timing was not right. In times of budget crisis at a local or national level, there seemed to be little support for providing funding for nutrition solutions $^{(23,29,53)}$.

Threaten litigation. If all else fails, three papers identified threatening corporations with litigation as a powerful strategy to influence policy change ${ }^{(18,36,53)}$. However, threat of litigation usually results in policy change from private industry rather than mandated government change. 


\section{Study limitations}

As with any systematic review, the scope of the initial literature search and publication bias may have resulted in relevant papers being missed. In addition, only papers that were peer-reviewed from high-income democratic countries were included in the review. The authors acknowledge important work in policy advocacy has occurred in developing countries and the grey literature; however, it was not within the scope of the review to incorporate those findings.

Despite these limitations, a rapid appraisal of such alternative literature suggests that, had the search been broadened, the results would not have altered in any significant way. In addition we believe that the synthesised data present a compelling guide for nutrition advocates who wish to better influence nutrition policy making in the future.

\section{Conclusion}

The frustration expressed by advocates around lack of policy change in nutrition frequently stems from their belief that policy making is a rational process in which evidence is used to assess the relative costs and benefits of options ${ }^{(57)}$. The present synthesis of the literature confirms that the reality is far from this. Consistent with the perspectives of policy scholars, the findings from the current review illustrate that evidence is only one component of many influencing policy change. For policy change to occur there needs to be political will, often underpinned by public will, for the proposed policy problem and solution. This requires policy entrepreneurs to work with coalitions of stakeholders to frame policy problems and communicate politically palatable solutions both to decision makers and the general public.

Many of the barriers identified in the review are consistent with those identified in political science theories, particularly Multiple Streams Theory, PunctuatedEquilibrium Theory and the Advocacy Coalition Framework. Most of the barriers were macro or structural issues, including the rise of neoliberal ideology, pressure from industry and government silos. These are issues that an advocate generally cannot change; however, it is imperative to acknowledge and understand these issues and consider how to work with them.

The suite of enablers presented in the current review highlights several areas where advocates can attempt to influence political and public will and ultimately change policy. These include framing problems based on values and emotions, and effectively coupling problems with well-considered solutions. It is important to appreciate that no one method will give results on its own and equally that undertaking all the documented strategies will not necessarily result in policy change, as policy making is often a complex and irrational process. However, the literature highlighted that the greater the variety of enabling strategies undertaken, the more likely advocates will be able to effect policy change. Further research into the effectiveness and impact of these strategies, particularly around using values and emotions in the context of public health nutrition policy, is warranted.

Despite the fact that few nutrition policy studies utilised political science theory in their analyses ${ }^{(10)}$, the enablers and barriers identified in the present review are consistent with political science theories which have been empirically tested in other fields of policy. The review has demonstrated that these theories are relevant to public health nutrition policy; therefore researchers and advocates are encouraged to incorporate the use of these theories to assist in refining their advocacy practice.

Advocacy is frequently said to be a combination of science and art. The current review has considered the 'science' behind what barriers to and enablers of policy change have been identified in the nutrition policy literature. However, it has also identified that effectively influencing policy change relies heavily on the 'art' of advocacy where nimbleness, flexibility, persistence, communication skills and the ability to identify the policy window opening come to the fore. The present review provides health professionals with a greater understanding of the barriers to and enablers of policy change, so that future advocacy efforts are more targeted with interventions tailored to address specific barriers and to make use of specific enablers.

\section{Acknowledgements}

Acknowledgements: The authors wish to acknowledge the guidance provided by Jennifer Browne, Karen Topp and Martin Reece in preparation of the manuscript. Financial support: K.C. is supported by an Australian National Health and Medical Research Council (NHMRC) Postgraduate Scholarship. Conflict of interest: None. Authorship: K.C. searched and reviewed the literature and drafted the manuscript. D.G. assisted in reviewing the literature. A.L., T.D. and D.G. offered valuable input and feedback on the manuscript. Ethics of human subject participation: Not applicable.

\section{References}

1. Roberto CA, Swinburn B, Hawkes C et al. (2015) Patchy progress on obesity prevention: emerging examples, entrenched barriers, and new thinking. Lancet 385, 2400-2409.

2. Hawkes C, Smith TG, Jewell J et al. (2015) Smart food policies for obesity prevention. Lancet 385, 2410-2421.

3. True JL, Jones BD \& Baumgartner FR (1999) Punctuatedequilibrium theory: explaining stability and change in American policymaking. In Theories of the Policy Process, pp. 97-115 [P Sabatier, editor]. Boulder, CO: Westview Press.

4. Kingdon J (1995) Agendas, Alternatives, and Public Policies. New York: HarperCollins. 
5. Swinburn B \& Wood A (2013) Progress on obesity prevention over 20 years in Australia and New Zealand. Obes Rev 14, Suppl. 2, 60-68.

6. Onyx J, Dalton B, Melville R et al. (2008) Implications of government funding of advocacy for third-sector independence and exploration of alternative advocacy funding models. Aust J Soc Issues 43, 631-648.

7. Cohen DEA (2001) Advocacy for Social Justice: A Global Action and Reflection Guide. Bloomfield, CT: Kumarian Press.

8. Jenkin G, Signal L \& Thomson G (2012) Nutrition policy in whose interests? A New Zealand case study. Public Health Nutr 15, 1483-1488.

9. Sabatier PA (1991) Toward better theories of the policy process. PS: Polit Sci Politics 24, 147-156.

10. Cullerton K, Donnet T, Lee A et al. (2015) Using political science to progress public health nutrition: a systematic review. Public Health Nutr (Epublication ahead of print version).

11. Cairney P (2015) How can policy theory have an impact on policymaking? The role of theory-led academic-practitioner discussions. Teach Public Admin 33, 22-39.

12. Lyn R, Aytur S, Davis TA et al. (2013) Policy, systems, and environmental approaches for obesity prevention: a framework to inform local and state action.J Public Health Manage Pract 19, 3 Suppl. 1, S23-S33.

13. Dixon-Woods M, Bonas S, Booth A et al. (2006) How can systematic reviews incorporate qualitative research? A critical perspective. Qual Res 6, 27-44.

14. Breton E \& De Leeuw E (2011) Theories of the policy process in health promotion research: a review. Health Promot Int 26, 82-90.

15. The Economist Intelligence Unit (2014) Democracy Index 2014: Democracy and Its Discontents. UK: The Economist Intelligence Unit.

16. Ritchie J \& Lewis J (2003) Qualitative Research Practice: A Guide for Social Science Students and Researchers. London: Sage.

17. Gale N, Heath G, Cameron E et al. (2013) Using the framework method for the analysis of qualitative data in multi-disciplinary health research. BMC Med Res Methodol 13, 117.

18. Kersh R \& Morone J (2002) The politics of obesity: seven steps to government action. Health Aff (Millwood) 21, 142-153.

19. Tillotson JE (2004) America's obesity: conflicting public policies, industrial economic development, and unintended human consequences. Annu Rev Nutr 24, 617-643.

20. Vogel EM, Burt SD \& Church J (2010) Case study on nutrition labelling: policy-making in Canada. Can J Diet Pract Res 71, 85-92.

21. Allender S, Gleeson E, Crammond B et al. (2012) Policy change to create supportive environments for physical activity and healthy eating: which options are the most realistic for local government? Health Promot Int 27, 261-274.

22. Caraher M, Carey R, McConell K et al. (2013) Food policy development in the Australian State of Victoria: a case study of the food alliance. Int Plan Stud 18, 78-95.

23. Ceccarelli A (2011) Review of policies adopted in 34 countries to improve diet and physical activity. Ital J Public Health 8, 156-171.

24. Shill J, Mavoa H, Allender S et al. (2012) Government regulation to promote healthy food environments - a view from inside state governments. Obes Rev 13, 162-173.

25. Crammond B, Van C, Allender S et al. (2013) The possibility of regulating for obesity prevention - understanding regulation in the Commonwealth Government. Obes Rev 14, 213-221.

26. Corvalán C, Reyes M, Garmendia ML et al. (2013) Structural responses to the obesity and non-communicable diseases epidemic: the Chilean Law of Food Labeling and Advertising. Obes Rev 14, 79-87.
27. Nathan S, Develin E, Grove N et al. (2005) An Australian childhood obesity summit: the role of data and evidence in 'public' policy making. Aust N Z Health Policy 2, 17.

28. Nestle M (1993) Food lobbies, the food pyramid, and US nutrition policy. Int J Health Serv 23, 483-496.

29. Milio N (1991) Toward healthy longevity. Lessons in food and nutrition policy development from Finland and Norway. Scand J Soc Med 19, 209-217.

30. Seed B, Lang T, Caraher M et al. (2013) Integrating food security into public health and provincial government departments in British Columbia, Canada. Agric Hum Values 30, 457-470.

31. Campbell AT (2012) The context for government regulation of obesity around the globe: implications for global policy action. World Med Health Policy 4, 1-48.

32. Brownell KD \& Warner KE (2009) The perils of ignoring history: Big Tobacco played dirty and millions died. How similar is Big Food? Milbank Q 87, 259-294.

33. Gilson Sistrom M (2010) Oregon's Senate Bill 560: practical policy lessons for nurse advocates. Policy Polit Nurs Pract 11, 29-35.

34. Dodson EA, Fleming C, Boehmer TK et al. (2009) Preventing childhood obesity through state policy: qualitative assessment of enablers and barriers. J Public Health Policy 30, Suppl. 1, S161-S176.

35. Field P \& Gauld R (2011) How do vested interests maintain outdated policy? The case of food marketing to New Zealand children. Open Health Serv Policy J 4, 30-38.

36. Freudenberg N (2005) Public health advocacy to change corporate practices: implications for health education practice and research. Health Educ Behav 32, 298-319.

37. Hobbs SH, Ricketts TC, Dodds JM et al. (2004) Analysis of interest group influence on federal school meals regulations 1992 to 1996. J Nutr Educ Behav 36, 90-98.

38. Nestle M (2003) The ironic politics of obesity. Science $\mathbf{2 9 9}$, 781-782.

39. Shelley JJ (2012) Addressing the policy cacophony does not require more evidence: an argument for reframing obesity as caloric overconsumption. BMC Public Health 12, 1042.

40. Dixon J, Sindall C \& Banwell C (2004) Exploring the intersectoral partnerships guiding Australia's dietary advice. Health Promot Int 19, 5-13.

41. Panjwani C \& Caraher M (2014) The Public Health Responsibility Deal: brokering a deal for public health, but on whose terms? Health Policy 114, 163-173.

42. Miller D \& Harkins C (2010) Corporate strategy, corporate capture: food and alcohol industry lobbying and public health. Crit Soc Policy 30, 564-589.

43. Norum KR (2005) World Health Organization's Global Strategy on diet, physical activity and health: the process behind the scenes. Scand J Nutr 49, 83-88.

44. Sadler RC, Gilliland JA \& Arku G (2014) Stakeholder and policy maker perception of key issues in food systems planning and policy making. J Hunger Environ Nutr 9, 1-15.

45. Craig RL, Felix HC, Walker JF et al. (2010) Public health professionals as policy entrepreneurs: Arkansas's childhood obesity policy experience. Am J Public Health 100, 2047-2052.

46. Gollust SE, Kite HA, Benning SJ et al. (2014) Use of research evidence in state policymaking for childhood obesity prevention in Minnesota. Am J Public Health 104, 1894-1900.

47. Kugelberg S, Jönsson K \& Yngve A (2012) Understanding the process of establishing a food and nutrition policy: the case of Slovenia. Health Policy 107, 91-97.

48. Blay-Palmer A (2009) The Canadian pioneer: the genesis of urban food policy in Toronto. Int Plan Stud 14, 401-416.

49. Johnson DB, Payne EC, McNeese MA et al. (2012) Menu-labeling policy in King County, Washington. Am J Prev Med 43, 3 Suppl. 2, S130-S135. 
50. Eyler AA, Nguyen L, Kong J et al. (2012) Patterns and predictors of enactment of state childhood obesity legislation in the United States: 2006-2009. Am J Public Health 102, 2294-2302.

51. Yeatman HR (2003) Food and nutrition policy at the local level: key factors that influence the policy development process. Crit Public Health 13, 125-138.

52. He FJ, Brinsden HC \& Macgregor GA (2014) Salt reduction in the United Kingdom: a successful experiment in public health. J Hum Hypertens 28, 345-352.

53. Freudenberg N, Bradley SP \& Serrano M (2009) Public health campaigns to change industry practices that damage health: an analysis of 12 case studies. Health Educ Behav 36, 230-249.

54. Bedore M (2014) The convening power of food as growth machine politics: a study of food policymaking and partnership formation in Baltimore. Urban Stud 51, 2979-2995.

55. Kjærnes U (2003) Experiences with the Norwegian nutrition policy. Appetite 41, 251-257.

56. Shelley D, Ogedegbe G \& Elbel B (2014) Same strategy different industry: corporate influence on public policy. Am J Public Health 104, 9-11.

57. Field P, Gauld R \& Lawrence M (2012) Evidence-informed health policy - the crucial role of advocacy. Int J Clin Pract 66, 337-341.

58. Johnson DB, Cheadle A, Podrabsky M et al. (2013) Advancing nutrition and obesity policy through cross-sector collaboration: the local farms - Healthy Kids Initiative in Washington State. J Hunger Environ Nutr 8, 171-186.

59. Freudenberg N, Mcdonough J \& Tsui E (2011) Can a food justice movement improve nutrition and health? A case study of the emerging food movement in New York City. $J$ Urban Health 88, 623-636.
60. Pollard CM, Lewis JM \& Binns CW (2008) Selecting interventions to promote fruit and vegetable consumption: from policy to action, a planning framework case study in Western Australia. Austr N Z Health Policy 5, 27.

61. Jou J, Niederdeppe J, Barry CL et al. (2014) Strategic messaging to promote taxation of sugar-sweetened beverages: lessons from recent political campaigns. Am J Public Health 104, 847-853.

62. Kurzer P \& Cooper A (2011) Hold the croissant! The European Union declares war on obesity. J Eur Soc Policy 21, 107-119.

63. Hawkes C, Ahern AL \& Jebb SA (2014) A stakeholder analysis of the perceived outcomes of developing and implementing England's obesity strategy 2008-2011. BMC Public Health 14, 441.

64. Kersh R (2009) The politics of obesity: a current assessment and look ahead. Milbank $Q$ 87, 295-316.

65. Loureiro MIG \& Freudenberg N (2012) Engaging municipalities in community capacity building for childhood obesity control in urban settings. Fam Pract 29, Suppl. 1, I22-I30.

66. Powles J, Wahlqvist M, Robbins J et al. (1992) The development of food and nutrition policy in Australia, with special attention to the State of Victoria. Asia Pacific J Clin Nutr 1, 47-60.

67. Good E, Hammond M, Martin C et al. (2010) An audit of local government planning tools for their potential use in addressing community food and nutrition issues. Health Promot J Aust 21, 5-11.

68. Cawley J \& Liu F (2008) Correlates of state legislative action to prevent childhood obesity. Obesity (Silver Spring) $\mathbf{1 6}$, $162-167$. 